\section{EN EL ORIGEN DE LA NOVELA CORTA DEL SIGLO DE ORO: LOS NOVELLIERI DESDE SUS PARATEXTOS ${ }^{1}$}

\author{
David González Ramírez \\ Universidad de Málaga \\ Departamento de Filología Española I y Filología Románica \\ Facultad de Filosofía y Letras, Campus de Teatinos \\ Universidad de Málaga. C.P. 29071, Málaga
}

(davidgr@uma.es)

\begin{abstract}
This paper is complementary to a previous article published in Arbor, "On the origin of the short story of the Golden Age: the novellieri in Spain". This work is an anthology, with a initial note indicating selection and publication criteria for a series of prologues, and dedications, and their censorship, in which problems translating some passages from Italian works that were difficult to assimilate in Counter-reformation Spain manifest themselves, the inquisitorial censors' suspicions are apparent, and we can also glimpse, in the final decades of the sixteenth century, the idea of doing something new, something that could awaken the genius of Spanish writers to rise to the level of Italian novels.
\end{abstract}

KEY WORDS:Straparola; Guicciardini; Bandello; Giraldi Cinzio; Italy; Spain; Golden Age.

Recojo en este trabajo, complemento documental de otro en el que he abordado las cuestiones que afectan al impacto y la recepción de los novellieri en España (González Ramírez, 2011), aquellos elementos paratextuales de más relieve para aquilatar la dimensión de varios aspectos en torno a la traducción y difusión de los escritores italianos que siguieron el modelo boccacciano y que fueron traducidos al castellano: Straparola, Guicciardini, Bandello y Cinzio. Se trata de una antología, en la que se incluyen censuras, prólogos y dedicatorias, a través de la que se pueden entender, en primer lugar, las dificultades con las que se enfrentaron los traductores, las licencias que en algunos casos adoptaron para edulcorar situaciones literarias de encendido tono $y$, en definitiva, las cortapisas que ellos mismos se impusieron antes de llevar su trabajo al Consejo para ser censurado y aprobado. En segundo lugar, y sin olvidar el contexto sociopolítico de la Contrarrefor-
ON THE ORIGIN OF THE SHORT STORY OF THE GOLDEN AGE: THE NOVELLIERI FROM HIS PARATEXTS

RESUMEN: Como complemento documental de otro artículo anterior publicado en Arbor, "En el origen de la novela corta del Siglo de Oro: los novellieri en España", el que ahora ve la luz es una una antología, con una nota inicial indicando los criterios de selección y edición de una serie de censuras, prólogos y dedicatorias en los que se manifiestan los problemas de traducción de algunos pasajes de obras italianas difíciles de asimilar en la España de la Contrarreforma, se aprecian los recelos de la censura inquisitorial, y también se adivina, en las últimas décadas del siglo XVI, un estado de conciencia de estar haciendo algo nuevo, algo que podia despertar el genio de los literatos para que España se pusiese a la altura de Italia en el terreno novelístico.

PALABRAS CLAVE: Straparola; Guicciardini; Bandello; Giraldi Cinzio; Italia; España; Siglo de Oro.

ma, los textos de los censores son una buena muestra de los recelos de la Iglesia ante ciertas extravagancias de la lengua que no podían permitir y que, en el mejor de los casos, cambiaban por términos más honestos, cuando no optaban por tachar ciertos pasajes completos que no se avenían a la ortodoxia católica o incluso a los intereses políticos de España.

Pero quizá lo que contenga más interés, desde un enfoque histórico-literario, es la determinación de algunos traductores por importar, a principios de los años setenta (en 1574 Truchado obtuvo la licencia real para su traducción de Le piacevoli notti de Straparola), un nuevo género que estaba teniendo un indiscutible éxito en su país de origen, y cuya difusión en España (según las palabras de Gaitán de Vozmediano en el prólogo a su traducción de Giraldi Cinzio en 1590) debía servir como incentivo para que nuestros 
literatos, en "tan venturosa edad cual la presente", se pusiesen a la altura de los italianos en el terreno novelístico. Este propósito verdaderamente es de singular notoriedad, pues tales traductores tomaron conciencia muy pronto de que en ellos descansaba el reto de iniciar una nueva era en la prosa novelística española; había que superar el estadio en el que esta se encontraba (el cuento novelado: Timoneda) para llegar a otro en el que las unidades novelísticas estuviesen más desarrolladas (la novela corta, que empezaría a cultivarse en España, intercalada en libros de diferente naturaleza, poco después de la propagación de los novellieri, y que alcanzaría su más alta expresión con las Novelas ejemplares y la legión de escritores que apareció a partir del lanzamiento de esta obra). Fueron estos traductores los que se propusieron que España quedase a la altura de Italia y los que a su modo crearon a Cervantes, al que pusieron cara a cara con Boccaccio.

Antes de pasar a especificar los criterios de edición, he decidido incluir como apéndice de esta selecta de textos la dedicatoria y el prólogo de dos obras que no han sido objeto de análisis en el estudio que enmarca esta compilación paratextual, pero que sin embargo comparten con las colecciones de Straparola et alii algunas de las ideas referidas en los párrafos introductorios. El primer libro es una traducción anónima de La Zucca del Doni, publicada en Venecia por F. Marcolini en 1551, exactamente en la misma fecha en la que vio la luz la versión original. La naturaleza de esta obra, que apenas debió de circular por la península (Nicolás Antonio, por ejemplo, no llegó a verla), fue definida concisamente por M. Chevalier (1981: 8) como

una miscelánea de varias noticias, una colección ordenada y desordenada de cartas encomiásticas, elogios burlescos, cuentos jocosos, observaciones satíricas, anécdotas divertidas y reflexiones morales. Ante todo es una recopilación de dichos de ingenios italianos, famosos u olvidados, entre los cuales ocupa preferente lugar el propio Doni, quien no vaciló en recoger e imprimir sentencias y donaires suyos.

Por tanto, la forma y el sentido de esta colección apotegmática se distancia de los libros de los novelistas postboccaccianos que a mediados del XVI comenzaron a salir de las imprentas, pero en este caso me interesa principalmente que se confronten los problemas de traducción que encontró quien trabajó en el traslado de La Zucca, así como las soluciones que aplicó, con aquellos escollos que tuvieron también que salvar quienes resolvieron difundir en castellano a Bandello o Cinzio. No podemos olvidarnos, por obvio que resulte, de que en el fondo de la cuestión estamos también valorando, además de la calidad literaria del texto, la competencia del traductor, quien tiene la necesidad justificativa de explicar las intervenciones que ha realizado en el texto para no traicionar su sentido originario.

Según se refiere en la dedicatoria inicial, el traductor de La Zucca (que se dice amigo del autor del texto y confirma haberlo trasladado al castellano por imperativo del conde Fortunato Martinengo Cesaresco) insistía en que prefería mantener "el sentido" del texto que ir atado "a la letra como los judíos"; privilegiaba la matización del significado de la palabra frente a la literalidad de la palabra en sí misma: "mi intención no ha sido en la tradución deste libro llegarme mucho a la letra, porque la letra mata más antes al espíritu que da vida, si no es cuando fuere menester". Para ello ponía algunos ejemplos de autores traducidos, cuyos textos, a su entender, eran un ejemplo palmario de los desbarres que un traductor puede cometer si se acerca demasiado al original y no toma las suficientes precauciones; con bastante donaire el traductor de $L a$ Zucca aseguraba que en ocasiones, "estando en España", solía leer "el Boccacio, pero sin duda las más no acertaba la entrada, y si a caso atinaba, me perdía por el libro, sin saber salir. Digo que en una hoja daba veinte tropezones, que bastaban confundir el ingenio de Platón".

No obstante, su labor no se redujo a buscar acomodo a aquellas expresiones que no encontraban una correspondencia literal con las de nuestra lengua, sino que en ocasiones, como también haría más tarde Jerónimo de Mondragón con L'hore di recreatione, el traductor de La Zucca reescribió algunas partes del texto, eliminando aquello que no se sujetaba a sus intereses e incorporando creaciones propias; Chevalier (1981: 22) declaró que este traductor sustituyó "los sonetos incluidos en los Postscrita", en cuyo lugar colocó "una glosa del conocido romance 'Más envidia he de vos, conde', glosa que será parto de su ingenio, y que nos revela una versión del romance distinta de las que conocemos por otra parte".

El segundo texto del que he extraído su prólogo es de otro carácter. Se trata de una traducción del impresor sevillano 
Andrea Pescioni de las Historias prodigiosas y ejemplares que recopilaron los franceses Boiastuau, Belleforest y Tesserant. Interesa ponerla en relación con los novellieri naturalmente por las similitudes de género y estilo, por sus compiladores (dos de los cuales trasladaron al francés las Historias trágicas de Bandello, de cuya traducción partió la elaborada por Millis) y también por el año en el que salen a la luz: $1586^{2}$. En pleno fervor por la novela corta italiana, cuando ya se habían traducido varias veces las dos primeras partes del Honesto y agradable entretenimiento de Straparola, y justo en el año en que se imprimen las Horas de recreación volcadas al castellano por Vicente de Millis Godínez, Andrea Pescioni traduce esta recopilación francesa, que se reeditó en Madrid en 1603.

Pescioni, que repetía las consideraciones del traductor de La Zucca para explicar su forma de obrar, confesaba también no haber "guardado el rigor de la letra" "en el traducir", "porque como cada lengua tenga sus frasis, no tiene el de la una buena consonancia en la otra. Solo he procurado no apartarme del sentido que tuvieron los que lo escribieron". Pero como nada se lo prohibía, metió su cuchara en el libro y recompuso lo que estimó oportuno; admitía que habia "dilatado otras algunas [cosas], por hacerlas más inteligibles, que estaban cortas, porque el original las suple con los retratos de las figuras que en él están debujadas, y en esta traducción no se han podido estampar por la carestía, así del artífice como de la obra". Menéndez Pelayo (1943 [1910]: 42-43, nota) advirtió que Pescioni había agregado al final

[...] tres historias de su cosecha [...]. Además intercala en el texto alguno que otro párrafo suyo [...]. Ocasionalmente traduce algunos versos de Virgilio, Horacio y Lucano, y también algunos de Ronsard (pp. 254, 255, 384, 395), de Boyssiero (p. 388) y de otro poeta francés (en lengua latina) cuyo nombre no expresa (p. 292).

En cualquier caso, al autor de los Orígenes de la novela no le parecian "estas versiones [...] inelegantes". Recordaba también Pescioni, como Gaitán de Vozmediano en el prólogo al lector de la colección de Giraldi Cinzio ${ }^{3}$, que había evitado ofender "las orejas de los píos" con asuntos deshonestos, y repetía exactamente el mismo argumento que Truchado (en el prólogo al lector de la primera parte de su traducción de Straparola ${ }^{4}$ ) o Vicente de Millis (en el que puso al frente de su traducción de Bandello) ${ }^{5}$ cuando afirmaba que a sus autores "les es concedido más libertad" en su patria natal, sujetándose con todo ello a la más pura doctrina filocatólica. Con las Historias prodigiosas y ejemplares tenemos una abigarrada recopilación de breves historias, ligadas muy hábilmente por Menéndez Pelayo con la Silva de varia lección del sevillano Mejía y otras de este mismo género; sin embargo, para lo que nos interesa, esta colección, originariamente reunida por tres franceses, apareció en pleno auge de las traducciones de los novellieri, por lo que su relación con este género queda acentuada desde su propia salida.

\section{Criterios de edición}

He aplicado, como es de rigor, una serie de normas uniformadoras, que en la mayoría de los casos son los criterios elementales que se adoptan para la edición de textos del Siglo de Oro. El hecho de que los textos sean originarios de ediciones impresas a lo largo de la segunda mitad del XVI (en 1551 aparece La Zucca del Doni, mientras que la reedición de Bandello es de 1596), y que no compartan, evidentemente, el lugar de impresión (componedores de talleres de Venecia, Madrid, Bilbao o Baeza estuvieron faenando con los originales, cada uno con sus usos y hábitos tipográficos), no afecta al estado de la lengua, muy inseguro aún a lo largo de esta centuria y en la siguiente, en la que todavía está evolucionando. Por tanto, y valga como descargo, en el marco de la pluralidad de los modi scribendi que coexisten en esta selección, he tratado de conservar en último término los valores fonéticos propios de la época, desvinculando del texto las variantes grafemáticas que carecen de significación para la historia de la lengua.

Como principios básicos y generales, he regularizado el uso de mayúsculas y minúsculas, he normalizado el empleo de las tildes según las normas vigentes y acomodado la puntuación a las exigencias del sentido. En este último punto hay que aclarar que la pertenencia de estos textos a personas poco habituadas a la escritura ha supuesto en ocasiones un grave escollo, pues a veces las formas asindéticas o las construcciones elípticas (en las que los autores "profesionales" tampoco escatimaban) han complicado esta labor. En estos casos siempre he tratado de interpretar el pasaje y ponerlo en cordialidad con la puntuación;

ARBOR Vol. 188756 julio-agosto [2012] 813-828 ISSN: 0210-1963

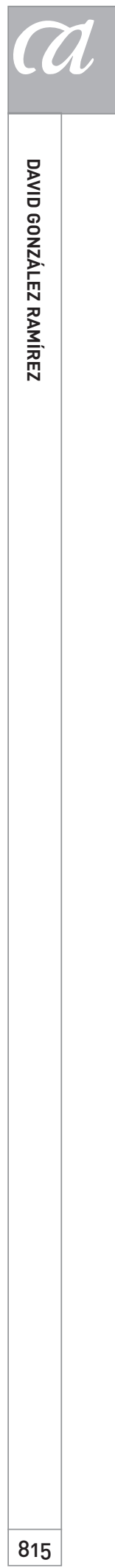


cuando me ha quedado alguna reserva, la he anotado al pie. Por su parte, para facilitar la lectura de los textos, he decidido desarrollar todas las abreviaturas tipográficas, incluidos casos como V. M. (que pasa a Vuestra Merced), $\&(y)$ o \&c (etcétera). Por otra parte, he intervenido en la aglutinación o separación de términos cuando ha sido preciso, y también he corregido, sin advertirlo, las erratas evidentes y otros descuidos de imprenta.

Con respecto al vocalismo, he distinguido, según se procede habitualmente, el uso de $y / i$ vocálica. El grafema $u$ lo reservo para el fonema vocálico, así como el $v$ para el consonántico. Algún caso que he hallado en el que una silaba ha diptongado posteriormente (trumphantes) también lo he conservado. Por su parte, he decidido mantener las oscilaciones en el timbre de las vocales átonas (regucijado, frasis). En el consonantismo también he ajustado los cambios procedimentales en estos casos, como la

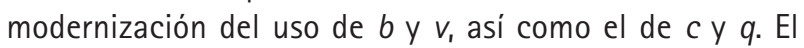
mismo criterio restaurador he mantenido para la $h$ (aora), que ha sido repuesta o eliminada según el uso actual. He unificado el uso de $s$, ss y $s$ alta, y neutralizado las variaciones entre los grupos $|j-x-g|$ y $|c-z-c ̧|$. He reducido las consonantes dobles (affición, illustre, corrolarios); si bien, he decidido mantener aquellos casos de betacismo (estremos).

Como antes he anotado, he decidido conservar aquellos casos grafemáticos que en la época tenían valor fonético. En este orden, he mantenido los dobletes (agora y ahora) y tripletes (asimesmo, ansimesmo y asimismo), los arcaísmos (felice; desagradado), los grupos consonánticos latinos (immortales, contradictión, sancta, escripto, respectado, dubda, augmento) y los grupos reducidos (letor, tradución), aunque he evitado aquellos grupos que carecen de implicación fonética, como ph (philosofophos) ${ }^{6}$, th (authoridad) y ch, para el que he colocado qu (anichilándote > aniquilándote) o c (christaliano > cristalino), según corresponda.

En las formas verbales, he respetado las variantes morfológicas detectadas (veemos, ternía, suscedió, engrandesce), así como algún caso infrecuente de vacilación en el timbre de las vocales (hubiéndonos), que he resuelto no corregir. También mantengo la palatalización de las líquidas en las formas de infinitivo con pronombre enclítico (ofendellos).
Conservo también las contracciones (deste, dél), eliminando, en algún documento en que aparecía, el apóstrofe (d'el); también he respetado los nombres propios españolizados, aun cuando oscilaban (Boccacio/Bocacio), y los usos de lengua propios del Siglo de Oro. Como es normal, no he intervenido en aquellos casos en desuso recogidos en el $D R A E$ (doctrina por adoctrina), y tampoco lo he hecho cuando no se ha discriminado entre dos formas homófonas (hierro en lugar de yerro).

Nada de lo dicho anteriormente afecta a la descriptio de las portadas, que se atiene a las normas de transcripción consensuadas por la bibliografía material.

\section{Paratextos: selección}

HONES | TO Y AGRADA | ble entretenimiento de da- | mas y galanes. | Compuesto por el señor loan Francisco | Caruacho cauallero Napolitano. $Y$ tradu- | zido de lengua Toscana en la nue- | stra vulgar, por Francisco | Truchado vezino | de Baeça. | [Grabado del impresor] | EN BILBAO. | Por Mathias Mares. I A costa de Iuan Ruelle mercader de libros. | 15807.

\section{[1]}

Epistola (ff. 3v-5)

\begin{abstract}
A la ilustre Señora doña Isabel Ana de Carvajal, mujer del ilustre señor don Cristóbal de Carauajal, gentilhombre de la boca de su Majestad, y veinte y cuatro de Baeza. Francisco Truchado, su servidor. Salutatem plurimam dicit.
\end{abstract}

Costumbre era muy celebrada entre los sabios egipcios, ilustre Señora, dedicar sus obras y escripturas a Mercurio, como a Dios y señor de las cosas del ingenio delicadísimo compuestas. Porque los murmuradores (a cuyo gusto no hay cosa dulce ni sabrosa) no tuviesen lugar, ni osasen soltar la rienda del abominable vicio de la murmuración, y porque todos en general las tuviesen en aquella veneración que convenía, y agora los que con suave y amoroso estilo han escripto y escriben, casi imitando a los de Egipto, dirigen sus trabajos a los más poderosos príncipes y señores, de cuya virtud y méritos, valor y autoridad, resulta, porque de tan felice dedicación nascen premios muy honrosos 
(dignos, por cierto, no de silencio), de los cuales es el uno que con su dedicación dan muestra a quien los dirigen de la afición y deseo que a su servicio tienen. El otro, que desta manera seguros a velas tendidas navegan por el tempestuoso golfo de la detractión, enderezando el curso de su navegación a puerto tan seguro que las inconstantes y satíricas olas no osan llegar temiendo contradictión y resistencia. Tercero, y más principal entre otros muchos, es que debajo de tales nombres y amparos eternizan sus obras con gloriosa fama y imortal memoria.

Asimesmo, ilustre Señora, aunque yo escritor no sea, quiero imitar tan célebre y antigua costumbre por el deseo que de gozar de tan honrosos premios tengo, y por la necesidad que esta mi traductión de tan importantísimo favor tenía, esto es, Señora ilustre, lo que mi honestísimo colegio, a Vuestra Merced dedicado, va buscando, aunque los mordaces comentos y satíricas sentencias digan que hago servicio a Vuestra Merced con obras olvidadas y sacadas de rincones ajenos; $y$ holgara que mi humilde ingenio echara la raya más alta, porque los que están a la memoria no hiciesen el oficio de las viles y venenosas arañas, que con solo su tacto convierten la dulce y sabrosa miel en amarga y mortal ponzoña. Mas procurando tan felicísimo remedio como es el amparo de Vuestra Merced, seguramente hago lo que soy obligado, como el buen padre que con la solicitud posible busca y procura estado tan honroso para su hijo, que el uno por el otro merezcan ser respectados. Porque, como los filósofos dicen, los libros son hijos del buen juicio que los compone. $Y$ así queda el tal compositor como padre, obligado a la disposición de tal empresa si quiere gozar de tan dichoso título y inmortal memoria. Esta es la verdadera disculpa de mi osado atrevimiento, suplicando a Vuestra Merced no desdeñe favorecer y recebir debajo de su amparo este pequeño servicio con la voluntad que le ofresco, pues favoresciéndole, engrandesce sus proprias cosas.

Vale.

[2]

Al discreto y prudente lector (ff. 5v-6)

No os maravilléis, amigo lector, si acaso hubiéredes leido otra vez en lengua toscana este agradable entretenimiento y agora le halláredes en algunas partes, no del sentido diferente, lo cual hice por la necesidad que en tales ocasiones debe usar, pues bien sabéis la diferencia que hay entre la libertad italiana y la nuestra, lo cual entiendo será instrumento para que de mi se diga que por enmendar faltas ajenas, saco en público las mías. Por tanto, prudentísimo lector, suplícoos las corrijáis y amigablemente enmendéis, porque mi voluntad y deseo fue acertar con la verdadera sentencia, y que vos, escardando estas peregrinas plantas, cogiésedes de ellas sus morales y virtuosas flores. Atrevime también a hermosear este honesto entretenimiento con estos últimos y ajenos versos de divino juicio compuestos, y usar de diferente sentido, no menos gustoso y apacible que el suyo proprio, porque así convino al atrevimiento, como en la segunda parte deste honesto entretenimiento veréis.

Vale.

I SEGVNDA PARTE, DEL HO- | nesto y agradable entretenimiento. Com I puesto por el jllustre cauallero, Francis- | co straparola de Caruacho, Napoli- | tano. Y traduzida de lengua tos | cana, en la nuestra vulgar, | por Frãcisco Truchado ve | zino de Baeça. | )?( | | Dirigido a la muy jllustre señora, doña | Leonor Carrillo de q̃sada, hija đl muy jllus | tre señor Pedro diaz Carrillo de quesada, | Capitã generl [sic] del Artilleria del rey | no de Napoles, y del consejo | Colateral de su Magestad. | :?: | CON PREVILEGIO. | | Impresso en Baeça, en casa de luan bap- | tista de Montoya. Año de mill \& | quinientos y ochẽta \& | vno. | (:)

[3]

Dedicatoria (ff. 4-5v)

A la muy ilustre Señora doña Leonor Carrillo de Quesada, hija del muy ilustre Caballero Pedro Díaz Carrillo de Quesada, Capitán general de la Artillería del Reino de Nápoles y del Consejo colateral de su Majestad.

Francisco Truchado, su servidor. Salutatem plurimam dicit.

Tiempo es ya, amado libro mío, desde tu tierna niñez con mis manos criado, que desde el uno al otro polo peregrinando hagas viaje, pues tu favorable ventura te ha puesto en tan dichoso estado que con casi natural sentido puedas conoscer lo que tu primogénito hermano dejó de gozar. No porque (también como tú) de su natural y dulce patria fue desterrado, ni aun por dejar de ser con regucijado contento

ARBOR Vol. 188756 julio-agosto [2012] 813-828 ISSN: 0210-1963 
en los reales, excelentes, ilustres, nobles y virtuosos palacios con laudable fama rescebido; mas por lo que a mi pluma, madre tuya en puridad, ruego no descubra, pues a ella, a mí y a tu primero hermano, las envidiosas y crueles parcas el delicado hilo de nuestro deseo arrebatadamente cortaron, dejándonos tan ajenos de favor cuanto ahora gozaremos de lo perdido y ambos merecemos lo por tu dichosa suerte ganado, pues siguro harás esta felicísima jornada en nombre de tan importante favor y amparo como te gobierna.

Camina, camina, libro mío, con atrevido ánimo, sin miedo de viles sátiras, envidiosos comentos, ni de mordaces y infernales glosas. No temas; teman aquellos a quien tus verdaderas sentencias (debajo de fingido y fabuloso palio cubiertas) tocan. Mas advierte, y con cuidado advierte, Entretenimiento mío, antes que esta dichosa jornada hagas, que con fiel memoria guardes los documentos que en el artículo desta tu partida te encargo, pues a ti y a mí tan de veras convienen. Usa dellos, consérvalos, te ruego, con eterno cuidado. Primeramente reconosce y entiende mi deseo, pues participas de lo más puro y secreto de mis entrañas; y con él corresponde en aquel dichoso momento que tu felicidad te guie y ponga en las ilustres manos, so cuya sombra vas encomendado, y de parte mía (por la tuya), disculpa mi osado atrevimiento y tuyo, suplicándole no cause admiración este tan humilde sacrificio en su alto entendimiento. $Y$ si el sustancial concepto del saber desea, lo pregunte a la razón, pues por ley suya manda que los virtuosos y honestos trabajos, porque in eternum sean respectados, conviene ser colocados en tan sublime asiento y impíreo trono, que nadie se atreva, ni aun con la imaginación, a ofendellos.

Por lo cual, procurando tan felicísimo remedio, tomé por partido dirigirte a la ilustre Señora doña Leonor Carrillo de Quesada, hija del memorable Caballero Pedro Díaz Carrillo de Quesada, segundo Marte, a quien por su dichoso entendimiento, ánimo, esfuerzo, raro valor y valentía (es parte de la defensa de nuestra católica fe y honra de la victoriosa España), se encomienda, sirviendo a los invictísimos césares, el emperador Carlo Quinto y Filipo Segundo, reyes y señores nuestros de eterna memoria, dejando en nuestros dichosos tiempos sus veces al esforzado Caballero Juan Váquez de Acuña, luz de la Bética, provincia y amparo del amparo tuyo y mío, hijo de la ínclita y famosa Baeza, madre de divinos ingenios y animosos guerreros, rincón siguro do la fe sancta se conserva y el real servicio tiene sempiterno asiento.

Advierte ansimismo, colegio mío, cuando llegues a las pías manos del sapientísimo lector que con amoroso espíritu por tu esmaltada floresta discurriere, de parte mía y tuya le supliques resciba el ánimo con que acertar deseo, y al envidioso, ingrato, escarnescedor y maldiciente idiota, que debajo del último centro de la tierra, aniquilándote, procurare darte sepultura, esforzadamente resistas sus satíricos y cobardes golpes con el acerado y fuerte escudo que te ampara; porque desta manera trunfantes cobraremos ánimo tal que sin miedo, en nombre de tu favor, en más dificiles, arduas y dificultosas batallas, salgamos victoriosos.

\section{Vade felix.}

\section{[4]}

Parescer del Maestro Juan López de Hoyos (ff. 270v-271)

\section{Muy poderoso Señor:}

Por mandado de Vuestra Alteza he visto este libro intitulado Segunda parte del honesto entretenimiento, traducido de lengua toscana por Francisco Truchado, vecino de la ciudad de Baeza. Él corresponde con su título, porque es como un jardín de honestas fictiones ejemplares y de buen discurso. Agora doce años vi la primera parte, y con esta queda bien satisfecho a la promesa que el auctor hizo. No hallo en él cosa que no sea muy gustosa y de buen ingenio. Van borradas algunas palabras por no proprias, o no castas; algunos renglones enteros, particularmente en las Tropelías, que son experiencias o secretos de ocultas filosofías, en las cuales decian que se esperasen signos o planetas. Para quitar supresticiones [sic] que dañan y ofenden en gran manera, con borrarlo queda lo demás conforme a su título de Honesto entretenimiento. Y ansí van borradas de modo que el impresor vea luego lo que va con censura.

Por lo cual, me paresce ser tal y digno de que Vuestra Alteza le haga esta merced, a quien nuestro Señor por muchos años prospere.

Deste estudio de Madrid, a nueve de julio de 1581 años.

Por mandado de Vuestra Alteza, su capellán el Maestro Juan López de Hoyos 
HORAS | DE RECREA | CION, RECOGIDAS | POR LVDOVICO GVICCIAR- | dino, noble ciudadano de Florencia: | Traduzidas de lengua Toscana. I En que se hallaran dichos, hechos, y exemplos de per- I sonas señaladas, con aplicacion de diuersas fa- | bulas, de que se puede sacar mucha doctrina. | [Grabado del impresor] | Con Licencia y Privilegio Real. | En Bilbao, por Mathias Mares, Impressor I d'el Señorio de Vizcaya. Año de 1586. | Esta tasado en [ ] maravedis.

\section{[5]}

Censura (f. 2)

Por mandado de los señores del Real Consejo he visto este libro intitulado Horas de Recreación, de Ludovico Guicciardino, traducidas de italiano en español, y le he conferido con su original, impreso en Venecia; y hallo que no tiene cosa contra la fe, ni contra buenas costumbres, ni deshonesta, antes para que vaya más casta la lectura le he testado algunas cosas que van señaladas y emendado otras, sin las cuales lo demás puede pasar, por ser lectura apacible; y al fin son todas apotegmas y dichos gustosos y de buen ejemplo para la vida humana, y puestas en un breve y compendioso tratado; y así me parece se le debe dar al autor la licencia y privilegio que pide.

En Madrid, a cuatro de julio. 1584.

Lucas Gracián

[6]

Epistola (ff. 3-4v)

A la muy ilustre Señora doña Ginesa de Torrecilla, mujer del muy ilustre Señor licenciado Duarte de Acuña, Corregidor del Señorío de Vizcaya.

Vincente de Millis Godínez, traductor de esta obra.

Es el escribir, ilustre Señora, una cosa con la cual se hace eterna la memoria de los hombres, y con que las personas señaladas quedan perpetuamente libres de la injuria del olvido, y como dice Marco Tulio en su Orador: "Es quien solo da testimonio de los tiempos, siendo luz de la verdad, vida de la memoria y maestro de la vida", pues hace que siguiendo el ejemplo de muchas cosas, los hombres conmunes y particulares, de estados bajos y humildes, vengan a imperar y reinar, y a estos suele dar ánimo para que con hechos immortales tengan codicia de ganar gloria, que nunca perece; $y$ aun a los soldados y personas que siguen la guerra, levanta los ánimos, para que estén aparejados a sufrir cualquier peligro a trueco de defender su patria, pues a un honroso morir se sigue luego la honra y fama. $Y$ demás esto, aparta a los malos de sus vicios y maldades, con temor que tienen de infamia perpetua por este mismo camino.

Y asi el intento del escribir ha siempre de ser procurar que los que leyeren lo que se escribe sigan lo bueno y huyan lo malo, conforme a lo cual viene a propósito lo que dice el apóstol, que todo lo que está escripto, se escribe para nuestra doctrina. Pues esta manera de escribir es en muchas maneras y tiene diversos nombres, porque unos lo hacen en historia, otros en poesía, tragedia, comedia, sátira, y otros en fictiones y fábulas, todas las cuales diferencias se hallarán en el breve y compendioso sujeto deste libro, debajo de rúbricas y ejemplos necesarios a nuestra vida con que podremos sacar el fruto y provecho que el autor pretendió, y yo en esta mi traductión querría y es mi intento que se siga.

Y pareciéndome que para sacarle esta primera vez a luz en nuestra lengua vulgar tenía necesidad, así él como yo, de salir debajo del amparo de quien las lenguas de los maldicientes (cuyo oficio proprio es decir mal de todo lo que veen, con razón o sin razón) estuviesen arrendadas, lo quise hacer así, por lo cual le dedico y ofrezco a Vuestra Merced, pareciéndome que con esto estaremos seguros desta persecución él y yo, y que Vuestra Merced, las horas que se hallare desocupada de otros negocios, le tomara por modo de recreación en sus manos, de lo cual se seguirán dos frutos; el uno, que debajo de tal amparo, yo estaré seguro y a él se le añadirá lo que le falta, con lo cual yo quedaré satisfecho de mi trabajo; y la memoria de Vuestra Merced será perpetua, lo cual recebiré en merced particular y muy señalada, y será darme ánimo para que pase con otras cosas que tengo comenzadas adelante, las cuales todas desde ahora dedico y ofrezco al servicio de Vuestra Merced, y quedo por perpetuo y muy aficionado servidor de Vuestra Merced, que

besa las ilustres manos de Vuestra Merced, su menor servidor.

Vicente de Millis Godínez

ARBOR Vol. 188756 julio-agosto [2012] 813-828 ISSN: 0210-1963

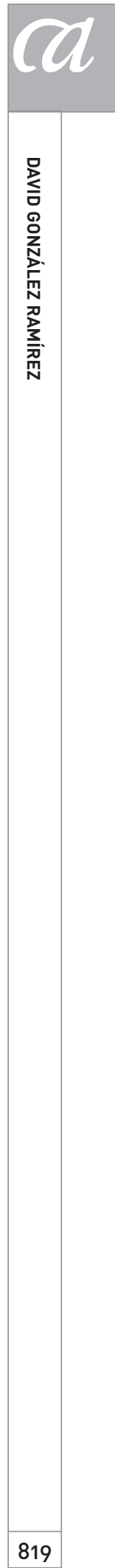


PRIMERA PARTE, | De los Ratos de recreacion, del | excelente Humanista M. Ludouico Guichiar I dino, patricio Florẽtino. Traduzidos de lẽgua | Italiana, i añadidos otros muchos $\tilde{q}$ se an pue- $\mid$ sto, en lugar de algunos $\tilde{q}$ se an dexado de tradu | zir, por ser de poco prouecho. E ilustrados con I muchas autoridades, de Poetas i otros graues | Escriptores Griegos, Latinos, Españoles, Ita- | lianos, i Franceses: por el Licenciado Hiero- | nymo de Mondragõ, Professor en am- | bos Derechos, en la insigne Vni | uersidad de Çaragoça. | Dirigidos al ilustrissimo señor dõ Luis Ximenez | de Vrrea Cõde de Aranda, Vizconde de Viota, Se- I ñor del Vizcõdado de Rueda i de la Señoria, o Te I nencia de Alcalaten \& c.l [Escudo del impresor] | Impressos en Çaragoça (con licencia) en casa | Pedro Puig, i luan Escarrilla, año 1588.

\section{[7]}

Prólogo al letor (ff. 16-18)

No dudo yo, prudente y benévolo letor, que otros muchos, a quien comúnmente llaman zoilos o detractores (cuyo veneno y rabia es tanta que hasta hoy no se ha hallado obra que a luz saliese que no la hayan contaminado), que con más elegancia y mejor estilo, guardando la fidelidad de la traducción, hubieran traído a debida perfición estos Ratos de entretenimiento. Pero viendo yo que hasta ahora ninguno dellos se ha movido a hacerlo, pareciéndoles por ventura cosa de tan poco momento que sus sutiles y delicados entendimientos no debían emplearse en ello, y viendo asimesmo que la obra es muy curiosa y de grande utilidad (lo que han muy bien mostrado otras naciones por haberla traducido y puesto en su propria lengua, teniéndola y estimándola en mucho), y también por las continuas importunaciones de algunos amigos y el gran deseo que tengo de aprovechar al bien común, posponiendo el temor de los que arriba dicho tengo, me puse a ello.

Helos traducido mediante el divino favor, como aquí se puede ver, y no sin grande trabajo, tanto por haberlos emprendido en las mayores ocupaciones de mis estudios, cuando por haber trabajado mucho en ellos, ilustrándolos con diversas autoridades, asi de los mejores poetas griegos, latinos, españoles, franceses, que he podido, como de los mesmos italianos y otros escriptores, demás de los que en ellos había, que eran tan pocos que apenas se echaban de veer, traduciéndolos en esta lengua del mesmo modo que antes en la suya estaban. He añadido también algunos Ratos algún tanto curiosos, poniéndolos en lugar de otros del autor que he dejado de traducir por parecerme de poca sustancia e indignos del sabio y grave letor. He dejado de poner los lugares de las autoridades por mí traídas, pues el autor en las suyas no los puso; aunque también le pudiéramos traer a él los más dellos. Los cuales, y todo lo demás que de nuevo se ha aumentado, he querido señalar con una estrella puesta en la margen, para que no se quite el trabajo y honra al que compuso la obra, y para que no piensen los arriba dichos que yo me quiero engrandecer con sudores ajenos.

Bien sé que luego me querrán dar en rostro la mucha licencia que me he tomado en querer añadir y quitar a la obra lo que no es permitido a traductor alguno, sino solo al autor de aquella. A esto respondo que puesto que yo usé destos términos, añadir y quitar, para declarar mi concepto, verdaderamente no lo hago, porque entonces se llama quitar y añadir cuando a una historia se le añaden o quitan cosas de aquellas que va contando, por las cuales se le viene a trocar y pervertir el sentido. Y como esta obra no es sola una historia, sino muchas, porque cada "rato" se puede tomar por una, y en ninguno dellos se toca la sentencia, antes bien se ha procurado sacarla lo más verdaderamente que se ha podido, como en su original se puede ver. Paréceme que en este particular quedo satisfecho.

Y a lo que podrán decir que no les traigo cosa nueva en lo que aquí se trata, se les puede satisfacer diciendo que harto nueva será, pues que jamás se vio en esta lengua y con semejante estilo. $Y$ asimesmo se les puede responder con la memorable sentencia del sapientísimo Salomón y célebre poeta Terencio diciendo que ninguna cosa se dice que ya antes no se haya dicho. $Y$ así no hay por qué murmuren dello, pues ya en sus tiempos estos excelentísimos varones sintieron esta falta. Lo que podrán notar en ello es que unos "ratos" parece que van muy dilatados y otros cortos. A esto dicho, que es así, pero que no hay tampoco que advertir en los que parecen quedar cortos; que, si bien se consideran, no haya tanto y por ventura más que en los que van muy dilatados. El lenguaje con que se escriben, tanto el del verso como el de la prosa, tendrán razón de decir que lleva poca elegancia, lo que concedo así por ser tradución, como por haber tenido más cuenta con sacar el proprio y verdadero sentido que las otras lenguas contenían, que con la sonoridad y elegancia.

Ruego pues al benigno y discreto letor, por la común humanidad, que tenga más cuenta con mi mucha afición y buen de- 
seo que de bien obrar y hacer servicio a todo el mundo tengo, que con mis faltas y descuidos, porque soy hombre, y como tal me es dificultoso y aun imposible el acertar en todo.

He querido sacar, como de paso, para solamente probar la mano, esta primera parte, la cual si cayere en gusto, prometo poner en la segunda o añadir esta con cosas de no menor curiosidad y entretenimiento; y si no, quedarse han, como dicen, en el saco para otra mejor feria.

HISTORIAS | Tragicas exemplares, | sacadas de las obras del Bandello | Verones. Nueuamente traduzidas de las | que en lengua francesa adornaron | Pierres Bouistau y Francisco | de Belleforest. | Contienense en este libro catorze Historias nota- | bles, repartidas por capitulos. | 48 | Año | [Grabado del impresor] | 1589 | Con Priuilegio Real. | En Salamãca, por Pedro Lasso impressor. | A costa de luan de Millis Godinez. | Esta tassado en

[8]

Aprobación (f. 2v)

He visto este primer libro de las Historias trágicas ejemplares, sacado de las obras del Bandello, nuevamente traducido de las lenguas italiana y francesa, que me fue remitido por los señores del Consejo de su Majestad; y habiéndole leído con atención, no hallo en él cosa que ofenda a la religión católica, ni malsonante, antes muchos y muy buenos ejemplos y moralidad, fuera de algunas maneras de hablar algo desenvueltas que en la lengua francesa, donde está más extendido, deben permitirse, y en la nuestra no suenan bien; y así las he testado y enmendado otras. $Y$ con esto soy de parecer que se puede imprimir este libro.

Fecha en Madrid, a XII de septiembre. 1584.

Juan de Olave

[9]

[Dedicatoria] (ff. 3-4v)

A don Martín Idiáquez, secretario del Consejo de Estado del Rey nuestro Señor

Cicerón, príncipe de la elocuencia, hablando de la Historia, dice que tiene por oficio manifestarnos las cosas pasadas, instruirnos en las presentes y aprovechar con su ejemplo en las futuras. Y lo principal en que se ocupa es en ponernos delante personas ilustres y señaladas, cuyos hechos y vidas fueron trabajos dignos de mucha honra y alabanza, para que viendo esto los presentes y los por venir, y considerando que los hechos heroicos permanecen siempre en la memoria de los hombres, se animen a emprender cosas semejantes. $Y$ no solo trae consigo la Historia este provecho, pero, si bien lo miramos, es una maestra que con gusto y dulzura nos enseña la verdad, aunque de ordinario el decirla suele causar desgusto y amargura. Y por concluir en una sola palabra, digo que la Historia es un dechado y espejo de la vida humana, donde si nos miramos con atención, podremos imitar lo bueno y huir lo malo.

Considerando pues el Bandello, natural de Verona, autor grave, el fruto y riquezas que se pueden granjear de la Historia (no con trabajo, sino con gusto de los que la leen como deben), recogió muchas y muy notables, unas acontecidas en nuestra edad y otras poco antes, queriendo en esto imitar a algunos que tuvieron por mejor escribir lo sucedido en su tiempo y debajo de príncipes que vieron, que volver a referir los hechos antiguos. Lo cual hace con toda llaneza y fidelidad, sin procurar afeites, ni colores retóricos que nos encubran la verdad de los sucesos; y destas escogí catorce, que me parecieron a propósito para industriar y diciplinar la juventud de nuestro tiempo en actos de virtud, y apartar sus pensamientos de vicios y pecados. $Y$ pareciome traducirlas en la forma y estilo que están en la lengua francesa, porque en ella Pierres Bovistau y Francisco de Belleforest las pusieron con más adorno y en estilo muy dulce y sabroso, añadiendo a cada una un sumario con que las hacen más agradables y bien recebidas de todos.

Poniendo pues los ojos en el provecho que se podría seguir a nuestra nación de la lectión destas historias, y que no hay lengua vulgar en que no anden escriptas, quise saliesen a luz en la nuestra, para que en ella no faltase cosa de que podría resultar tanto provecho y utilidad. Y determinado de hacerlo, por consejo de muchos amigos que a ello me persuadieron, también determiné tomar por amparo y protector suyo a Vuestra Merced, entendiendo que así a la obra como a mí nos convenía, para que viéndola dedicada a Vuestra Merced, aunque se conozca que las faltas que en ella hubiere se han de atribuir a mí, se suplan debajo de la sombra de Vuestra Merced, de cuya autoridad, letras, virtud y valor está el mundo tan satisfecho. Y así, le suplico reciba este don con el amor y benignidad que espero, te-

ARBOR Vol. 188756 julio-agosto [2012] 813-828 ISSN: 0210-1963

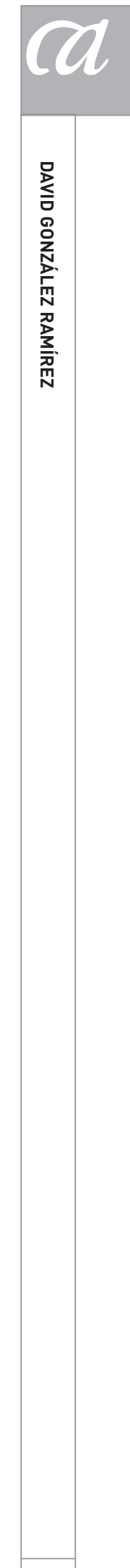


niendo cuenta con la voluntad con que se ofrece y no con la poquedad de lo que se da. Que mirando a lo primero, yo quedaré satisfecho y la obra no temerá ir por donde quiera; y será darme ánimo para pasar adelante con lo comenzado, Ilevándolo al cabo sin perdonar a trabajo alguno. Con que quedo por perpetuo servidor de Vuestra Merced, a quien nuestro Señor guarde y dé la salud que desea.

De Salamanca, en ocho de julio de 1589.

Vicente de Millis Godínez

[10]

Al lector (f. 5)

El Bandello varonés escribió muchas historias trágicas sucedidas en su tiempo o poco antes para con ellas apartar a los que las leyesen de vicios y peligros a que está sujeta la vida humana. $Y$ es de presuponer una cosa que él mismo refiere, que no dice cosa que no la haya visto, informádose o tenido relación cierta de personas fidedignas y escrituras auténticas; y si es así, como lo creo, debe ser tenido en mucho su trabajo y invención. Púsolas en su lengua italiana, aunque escribiéndolas sucintamente y en relación breve, y viendo Pierres Bovistau y Francisco de Belleforest, franceses (añadieron a cada una un sumario para mejor entendimiento de lo que se contiene en ellas), el provecho que se podía seguir de que esta obra anduviese en su lengua, las adornaron y pusieron en forma de historia, haciendo el uno las seis primeras y el otro imitándole en las demás, con tal arte y buena orden que me pareció no sería razón que la nuestra careciese de cosa de que se le podía seguir tanto fruto, mayormente que no hay ninguna vulgar en que no anden, y así las recogí, añadiendo o quitando cosas superfluas y que en el español no son tan honestas como debieran, atento que la francesa tiene algunas solturas que acá no suenan bien. Hallarse han mudadas sentencias por este respeto, y las historias puestas en capítulos, por que la lectura larga no canse. Recebirá el lector este trabajo con la voluntad con que se le ofrece y aprovecharse ha sacando dél el fruto que se espera.

HISTORIAS | TRAGICAS | exemplares, sacadas del Bandello Verones. | Nueuamente traduzidas de las que en len- I gua Francessa adornaron Pierres | Bouistau, y Francisco de | Belleforest. | Contienense en este libro catorze Historias notables, I repartidas por capitulos. | 15 [Grabado del impresor] 96 | CON LICENCIA. | En Madrid, en casa de P.
Madrigal. | Acosta de Claudio Curlet Saboyano mercader I de libros.

[11]

[Dedicatoria] (f. 4-4v)

Al Conde Alfonso Logosco de la Mota, embajador del serenísimo duque de Saboya, acerca del Rey católico don Felipe II. Claudio Curlet Saboyano, librero, salud, etcétera.

Hallándome en esta corte a cierto pleito he impreso estas Historias trágicas por ser letura apacible y gustosa; y pensando a quién las habia de dirigir, ninguno me ocurrió a quien por más título lo debiese que a Vuestra Señoría, siendo, como soy, natural vasallo del serenisimo duque (cuya persona Vuestra Señoría representa), y Vuestra Señoria, tan mi señor; y que siendo amparo en estos reinos de los Saboyanos, no nos dejara por su benignidad de amparar este librillo, y a mí con él, no mirando a la poquedad dél, ni a mi atrevimiento, sino a la buena voluntad y deseo de servir con que le ofrezco a Vuestra Señoría, a quien suplico lo acepte con su acostumbrada magnanimidad, como el Rey Artajerjes el agua que el pastor le ofreció en las manos.

Guarde nuestro Señor a Vuestra Señoría muchos años en su santo servicio, amén.

En Madrid, a 21 de julio. 1596.

PRIMERA PARTE | DE LAS CIEN NOVE- | LAS DE. M. IVAN BAPTISTA GI | raldo Cinthio: donde se hallaran varios discursos de en- I tretenimiento, doctrina moral y politica, y senten- | cias, y auisos notables. Traducidas de su len- | gua Toscana por Luys Gaytan de I Vozmediano. | Dirigidas a don Pedro Lasso de la Vega, Señor de la villas de I cuerna y Batres y los Arcos. | Impresso en Toledo, por Pedro Rodriguez. 1590. | A costa de lulian Martinez mercader de libros.

\section{[12]}

[Dedicatoria del traductor] (ff. 3-3v)

A don Pedro Laso de la Vega, Señor de las villas de Cuerva, y Batres, y los Arcos

Considerando que, como la experiencia nos lo muestra, aunque una pintura no sea de famoso y excelente artífice 
cobra nombre, reputación y estima acerca de los que la ven puesta en lugar ilustre y honroso, y que a esta causa me convenía procurar lo mesmo en la tradución de este libro, quise dedicarle a Vuestra Merced para que gane en sus manos lo que hubiere perdido en las mías. Cosa en que nadie pondrá dubda, pues fuera de ser el de Vuestra Merced uno de los más nobles y antiguos linajes de España, la rara virtud que le adorna y el singular ingenio que le ilustra, le hacen harto más digno de honor y nombre eterno que los famosos hechos de sus mayores. La gloria de los cuales, según dice Juvenal, Ovidio y otros muchos poetas y filósofos, no se hereda con los títulos, con la hacienda, ni con los cargos y oficios.

Pero no obstante eso, habemos de confesar que las virtudes de los padres son parte para que los hijos las tengan, pues de ordinario vemos que de los fuertes nacen sus semejantes y de los virtuosos, lo mismo. $Y$ puesto que la virtud no tenga necesidad de la nobleza, por ser sola ella la que ennoblece al hombre, con todo eso, así como el fino esmalte hace más rico, de más valor y más hermoso el oro, así hallándose estas dos calidades juntas en una persona, resplandecen más y son de mayores quilates.

Como lo vemos en Vuestra Merced, que mirándose como en cristaliano espejo en las obras de sus pasados, en especial de Garci Laso de la Vega, su padre (hijo de don Pedro Laso y sobrino de Garci Laso, el mayor de nuestros poetas), las ha imitado de manera que llegan al punto de perfección que todos en las suyas procuran. Mas ¿para qué gasto tiempo en contarle a Vuestra Merced sus virtudes y alabanzas proprias, si ha de ser más dificultoso el saberles dar fin que principio? Más acertado será dejarlo, pues claramente veo que es mayor su merecimiento que mi alabanza, más poderosa su gloria que mi lengua y más eficaz su valor que mi pluma. Solo quiero suplicar reciba debajo de su amparo este libro y al que con tanta voluntad se le ofrece, para que el favorecido valga lo que sin esto no vale; y yo, animado a la empresa de mayores obras, sirva a Vuestra Merced como debo, a quien nuestro señor guarde con el augmento de vida y estado que este su servidor desea.

De Toledo, 26 de agosto de 1589.

Luis Gaytán de Vozmediano
[13]

Prólogo al lector (ff. 4-5)

Una de las cosas más dificultosas, según sentencia de Demóstenes, es haber de contentar a muchos. Porque así como los ánimos y cuerpos de los hombres nunca son conformes y semejantes en todo, y por maravilla en alguna parte, pues a unos agrada lo dulce, y a otros, su contrario; estos se acomodan bien a la lucha, y aquellos, a la carrera; asi en los ingenios y en las inclinaciones se halla también desemejanza notable. Porque hombres hay que no les contenta, ni alaban, sino lo que ellos pueden y saben hacer, y otros a quien parece mal la abundancia de sentencias y palabras, quiriendo más la sequedad enfadosa que la copia elegante; cuáles son inclinados a historias verdaderas, y cuáles a cuentos fabulosos. $Y$ todas al fin son cosas de que no debemos maravillarnos, pues provienen de ser tantos y tan varios los gustos y pareceres como diversos y muchos los hombres, sino tener por conclusión averiguada que el que se pone a escrebir es casi imposible que pueda contentar a todos.

Lo mesmo entiendo que debió considerar Juan Baptista Giraldo Cinthio cuando quiso componer esta obra, el cual, viendo que si escrebía historia sola como la que hizo de Ferrara no granjearía sino las voluntades de aquellos pocos que le son aficionados, y si cosas de poesía, como el Hércules en estancias, algunas tragedias, y muchos sonetos y canciones que compuso, no gustarian dello sino los que naturalmente se inclinan a leerlo, quiso escrebir estas Cien novelas, con que entendió agradar generalmente a todos: a los amigos de historia verdadera (con la que pone esparcida por toda la obra), a los aficionados a filosofía (con el Diálogo de amor, que sirve de introdución en esta Primera parte, y los tres Diálogos de la vida civil, que están al principio de la segunda), a los que tratan de poesía (con las canciones que dan fin a las décadas) y a los que gustan de cuentos fabulosos (con ciento y diez que cuentan las personas que para esto introduce, pues en todos debe de haber muy pocos verdaderos, puesto que muy conformes a verdad y a razón, ejemplares y honestos).

Honestos digo, respecto de los que andan en su lengua, que para lo que en la nuestra se usa no lo son tanto que se permitieran imprimir sin hacer lo que se ha hecho, que fue quitarles lo que notablemente era lascivo y deshonesto. Para lo cual hubo necesidad de quitar cláusulas enteras y aun toda una novela, que es la segunda de la primera

ARBOR Vol. 188756 julio-agosto [2012] 813-828 ISSN: 0210-1963

(n)


década, en cuyo lugar puse la del maestro que enseña a amar, tomada de las ciento que recopiló el Sansovino. Esto y otras cosas semejantes hallará quitadas y mudadas el que confiriere la tradución con el original, especialmente el saco de Roma, que se quitó por evitar algunos inconvenientes que pudieran seguirse de imprimirle. No quise poner en esta Primera parte más de veinte novelas y la introdución con sus diez ejemplos, viendo que hacen bastante volumen para un libro como este, que, por ser para todos, ha de ser acomodado en el precio y en el tamaño.

Moviome a sacarle a luz el ser de gusto y entretenimiento, y ver que no hay en nuestra lengua cosa deste sujeto que sea de importancia, pues son de harto poca los que llaman Entretenimientos de damas y galanes; y pesábame que, a falta de otros mejores, los tomase en las manos quien alcanzó a ver las Novelas de Juan Bocacio que un tiempo anduvieron traducidas, pues va de uno a otro lo que de oro terso y pulido a hierro tosco y mal labrado. Ahora también han salido algunas de las Historias trágicas traducidas del francés, que son parte de las Novelas del Bandello, autor italiano, y no han parecido mal. A cuya causa entiendo que ya que hasta ahora se ha usado poco en España este género de libros, por no haber comenzado a traducir los de Italia y Francia, no solo habrá de aqui adelante quien por su gusto los traduzca, pero será por ventura parte el ver que se estima esto tanto en los extranjeros para que los naturales hagan lo que nunca han hecho, que es componer novelas. Lo cual entiendo harán mejor que todos ellos, y más en tan venturosa edad cual la presente, en que como vemos tiene nuestra España no un sabio solo, como los hebreos a Salomón, ni dos, como los romanos (conviene a saber: Catón y Lelio), ni siete, como los griegos (cuyos nombres son tan notorios), sino millares dellos cada ciudad que la ilustran y enriquecen.

Entretanto yo, que he dado principio a la tradución de esta obra del Giraldo, la iré prosiguiendo hasta el fin, si viere que se recibe con el gusto y aplauso que el ingenio de su auctor pide y mi trabajo y voluntad merecen.

\section{[Aprobación]}

Muy poderoso Señor:

Por mandado de Vuestra Alteza he visto esta Primera parte de las cien novelas, de Juan Baptista Giraldo Cinthio, traducidas de toscano en castellano por Luis Gaitán de Vozmediano, y me parece que, por ser de ingenio y estar traducidas en buen lenguaje (quitando el primer cuaderno del saco de Roma, por algunos respectos de consideración), se puede dar el previlegio y licencia pedida.

En Madrid, a seis de noviembre de 1589 años.

Tomás Gracián Dantisco

ApÉNDICE

[1]

\section{LA | ZVCCA | DEL | DONI | En Spañol.}

El título figura en la parte central de una portada arquitectónica. Del colofón se pueden extraer los datos de la edición: "Venetia, per Francesco Marcolini, il mese d'ottobre, 1551".

[Dedicatoria] (ff. 2-5v)

Al ilustre señor Juan Batista de Divicii, abad de Bibiena $y$ de san Juan in Venere.

Entre las virtudes, ilustre Señor, que a un hombre hacen perfeto y acabado, una y muy principal es el agradecimiento, porque por él venimos a caber con todos, ganamos nuevas amistades, conservamos las viejas y de los enemigos hacemos amigos. Tiene tanta fuerza esta virtud que a los hombres cobardes hace muy osados en el dar; a los que reciben, regocijados en el pagar; y a los avaros, liberales. Buena cosa es ser agradecido y malísima ser ingrato. ¿Qué cosa hay más fuera de razón, ni tan contra derecho, como no pagar lo que se debe? Ningún hierro hay digno de mayor pena que este. Enoja a Dios (si puede caber enojo en cosa tan fuera dél), ofende a los hombres y finalmente a todos hace mal estómago. Luego cosa es (hubiéndonos Dios hecho un esmalte de sus perfeciones y bondad) a nuestro natural muy conforme esta virtud; y como lo sea, todos los que tratan della han de tener el medio y apartarse cuanto pudieren de los estremos, de suerte que no sean tan presurosos que luego del pie a la mano procuren salir de deuda, ni tan tardíos que jamás se acuerden de pagar lo que son obligados, porque así como lo uno es vicio, lo otro deja de ser virtud. 
Decía Séneca que de hombre de poco valor es querer hacer luego sin más dilación recompensa del beneficio recebido; y así es, por cierto, porque este tal quiere librarse presto (como parece) de toda obligación para con sus amigos, porque no parezca que con la dilación se le haya cargado la deuda. Por tanto, por huir destos inconvenientes es muy necesario tenernos hacia el medio y buscar tiempo, sazón y lugar para regraciar con obras o palabras a los que nos han hecho algún beneficio; y si con obras no podemos, por no tener aparejo, ni posibilidad, a lo menos mostrarles con buenas palabras el deseo que tenemos de cumplir con obras. Siendo yo, pues, deudor por tantas partes a Vuestra Merced, no he querido ser de los que pagan luego, o por mejor decir, no he podido serlo, ni tampoco de los que tardan en pagar, por no ser tachado de hombre desconocido.

En fin, que queriendo yo tener el medio, por no errar, suscedió que estando con el Doni, hombre, como Vuestra Merced sabe, agudo, venimos a hablar de La Zucca, que él no ha muchos dias hizo estampar. Roguele que me enviase una, porque no había probado calabazas este año; él lo hizo como amigo. Agradome la materia e argumento del libro, que sin duda, para entretener una conversación, un rato, es de los buenos que he leído; encarecisele tanto al señor conde Fortunato de Martiniengo, que él, como deseoso de saber nuestro lenguaje, allende de ser tan aficionado a la nación española, me rogó con gran instancia le tradujese, poniéndome delante la utilidad y provecho que de alli redundaría a muchos que carescen de la lengua italiana. Conoscida su voluntad (aunque querría más escribir de mío, si supiese, que traducirlo de otros), le otorgué lo que me pidió.

Acordeme después que, para hombre que podía poco, este era el tiempo, lugar y coyuntura donde podría mostrar la voluntad que tengo de servir a Vuestra Merced, pagando en parte lo que en todo no puedo; y así determiné dedicarle este pequeño trabajo del traslado de $L a Z u c c a$, dado que el original el Doni no le haya consagrado a ninguno. Porque, demás de mostrar que reconozco la deuda, la obra vaya más segura y amparada debajo de la sombra y favor de Vuestra Merced, y así le suplico la reciba en servicio, que yo soy cierto que le agradará, confiado de su ingenio y buen natural; y si no le contentare, será más por el nombre que por lo que la calabaza contiene.

Está llena de muchas y provechosas sentencias, de muy buenos ejemplos, de sabrosos donaires, de apacibles chis- tes, de ingeniosas agudezas, de gustosas boberías, de graciosos descuidos, de bien entendidos motes, de dichos y prestezas bien dignas de ser sabidas, de manera que por ella se puede decir: "So el sayal ay al". Lo que se vee paresce cosa de burla, y de lo que no se paresce, todo, o la mayor parte, es de veras. Es un repertorio de tiempos, una red barredera que todos los estados, oficios, edades, recoge en sí. Finalmente es un Sileno de Alcibiades: a todos avisa, con todos habla de suerte que asi grandes como pequeños, ricos y pobres, doctos y ignorantes, señores y los que no lo son, viejos y mozos, y en conclusión, desde el Papa hasta el que no tiene capa, sin sacar ninguno, pueden sacar desta Zucca tanto zumo que salgan llenos y la calabaza no quede menguada.

Una cosa quiero advertir a quien este librillo leerá: que $L a$ Zucca en el vulgar italiano tiene tanta fuerza que apenas se puede traducir en otra lengua con tanta. La razón es porque cada lengua tiene sus particulares maneras de hablar, de manera que lo que suena bien en una, volviéndolo en otra, palabra por palabra, suena mal, como paresce por muchos libros traducidos en esta lengua de italiano, y en los que de latín y griego se traducen en castellano. Pero como el romance nuestro sea tan conforme al toscano, por ser tan allegado al latín (aunque en algo difieran, no en todo), no dejo de confesar que la lengua toscana no sea muy abundante, rica y llena de proverbios, chistes y otras sentenciosas invenciones de hablar, las cuales en nuestro castellano ninguna fuerza tendrian, como si dijésemos, de uno que quieren ahorcar, "han mandado los alcaldes que le lleven a Fuligno". Esta palabra tiene dos sentidos: o que le mandan ir a una ciudad que se llama Fuligno o que le mandan ahorcar (fune quiere decir soga o cordel, ligno, leño o madero).

Quien quisiese dar esta fuerza en castellano ternía bien que hacer de manera que es menester que en algunas partes tomemos el sentido y le volvamos en otras palabras, y no queramos ir atados a la letra como los judios; por lo cual, han hecho muchos errores algunos intérpretes. Es averiguado, como paresce, que ni ellos entendian los originales, ni sus traslados los que los leen; antes sé decir que quedan embelesados, paresciéndoles que leen cosas encantadas y sin pies ni cabeza, a cuya causa vienen a ser tenidos en poco los autores por aquellos que los leen mal traducidos en otra lengua peregrina, allende que confunden con palabras groseras el sentido que el autor pretende

ARBOR Vol. 188756 julio-agosto [2012] 813-828 ISSN: 0210-1963

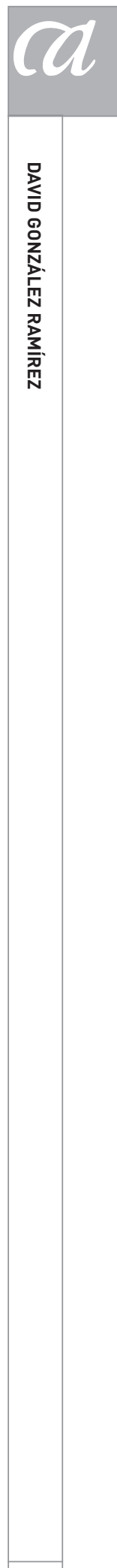

825 
y hacen una disonancia tan grande que despertarian la risa al más grave y Saturno, y sacarian de sus casillas al más sufrido que se hallase. Por estos se podría decir: "Habló el buey y dijo mu". Quien quisiere experimentar lo dicho, lea la tradución del Boccacio, y del Plutarco, Quinto Curcio y otros muchos autores de los cuales por no ser prolijo no hago memoria. Algunas veces solía yo leer, estando en España, el Boccacio, pero sin duda las más no acertaba la entrada, y si a caso atinaba, me perdía por el libro, sin saber salir. Digo que en una hoja daba veinte tropezones, que bastaban confundir el ingenio de Platón.

He usado, ilustre Señor, destos preámbulos y corolarios para venir a este punto; conviene a saber, que mi intención no ha sido en la tradución deste libro llegarme mucho a la letra, porque la letra mata más antes al espíritu que da vida, si no es cuando fuere menester. Desta manera, yo fiador que la calabaza no salga vana, ni los que la gustaren vuelvan desagradados, ni mal contentos o confusos (pero dirá alguno: "en fin, es calabaza"), yo lo confieso, pero no por eso se ha de dejar de comer della, que ni ella comida hará mal estómago, ni el nombre ha de poner miedo a ninguno. Escrito está que infinito es el número de las calabazas, y según mi opinión no hay hombre que no lo sea, pero esta es la diferencia que unos disimulan más que otros, y aún veemos muchas veces, que en la sobrehaz algunos parescen y son tenidos por calabazas, y no lo son del todo (aunque, como he dicho, lo sean en algo).

Todas las cosas perfectas no son estimadas por de fuera. Naturaleza es tan sabia y discreta que puso la virtud dellas debajo de muchas llaves. Como paresce en los cielos y en la tierra, en la cual veemos que los árboles tienen su virtud ascondida, y asimismo el oro y los otros metales, ¿qué diremos de las piedras preciosas que se hacen en la mar? Pues lo mesmo podremos decir que acaesce entre los hombres, que los más sabios tienen su prudencia más ascondida, aunque en lo exterior sean tenidos por livianos. A estos soy cierto que no les dará hastío la corteza de la calabaza, antes se holgarán de tocarla, porque saben que leyéndola gozarán de los secretos interiores, que debajo de la corteza, o por mejor decir, del hombre de calabaza, están encerrados.

Reciba pues Vuestra Merced este pequeño presente de $L a$ Zucca o calabaza, que por haberla el Doni cortado fresca con el rocío de la mañana, temo que de mis manos no salga seca y sin zumo. Verdad es que he trabajado de conservarla en aquella frescura, ya que no he podido mejorarla: que el Doni la cortó de su proprio jardín. Ella va a buena coyuntura, que según me paresce agora es el tiempo de las calabazas en esta tierra, aunque en otras sea en setiembre. Pienso que tomará Vuestra Merced tanto gusto que perdonará parte de la deuda en que estoy y aceptará el presente en servicio.

Nuestro Señor su ilustre persona guarde y prospere por muchos años.

Venecia, a XXV de setiembre. MDLI.

[II]

HISTORIAS. | PRODIGIOSAS | Y MARAVILLOSASAS | DE DIVERSOS SVCES- | sos acaescidos en el Mundo. | Escriptas en lengua Francesa, por Pedro Bouistau, Claudio tesserant, y Francisco Beleforest. | Traduzidas en romance Castellano, por Andrea | Pescioni, vezino de Seuilla. | Dirigidas al muy Ilustre señor Licenciado Pero Diaz de I Tudanca, del Consejo de su Magestad, y Alcal- | de en la su casa y Corte. | [Grabado del impresor] | CON PRIVILEGIO. | En Medina del Campo | Por Francisco del Canto. | A costa de Benito Boyer, mercader de libros. | M.D.LXXXVI.

\section{Prólogo \\ Al cristiano lector}

Algunos años ha que vi la primera parte de aquestas Historias prodigiosas que en lengua francesa escribió el docto y ilustre varón Pedro Bovistau, señor de Launai, y me pareció obra que merecía estar escripta en los corazones de los fieles, porque con singular erudición, y con vivos y maravillosos ejemplos, nos enseña y doctrina. $Y$ luego me dio voluntad de traducirla; y por entonces no pude poner en ejecución mi deseo, porque hallé que aquel libro estaba imperfecto y defectuoso de algunas hojas, de que habia tenido culpa la ignorancia de alguno, que por no haber conocido aquella joya, se las había quitado para deflorarla de algunas pinturas y retratos que en el principio de cada capítulo tenía (que la curiosidad del auctor había hecho retratar para con mayor facilidad representar a los ojos de los lectores las historias y casos que en ellos se contenian). De que recebí no pequeño desgusto, y procuré que de Francia me fuese traído otro de aquellos libros; y 
se pasaron muchos meses antes que hubiese podido conseguir mi intento.

Pero con la mucha diligencia y cuidado que en ello puse, le consegui, y aun aventajadamente, porque me fue traído el original de que he sacado aquesta mi tradución, que no solo lo fue de aquella obra que tanto había deseado, mas aun tuvo añadidas otras tres partes que tratan del mismo sujeto, que han escripto dos eruditos varones, cuales son Claudio Tesserant y Francisco Belleforest, que como viesen ${ }^{8}$ (por causa de nuestras corruptas y abominables vidas) las amenazas que continuamente Dios nos muestra por medio de varias señales y prodigios, nos advierten y amonestan que nos emendemos, con apercebimiento que si no lo hiciéremos no dudemos de que él nos castigará con riguroso azote, como lo suele hacer a los que le son rebeldes, así como lo enseñan con infinidad de ejemplos de casos acaecidos en todas las edades del Mundo, desde que él le crió hasta agora.

Fue cierto grande el contento que con él recibí, y entendí que mi deseo debía ser acepto a Dios, pues me le había cumplido con tanto colmo; y así di principio a la obra, que no me fue tan fácil como me había persuadido. Pero, en fin, con el favor divino y con la continuación de algunos meses llegué a darle entero cumplimiento, de que, tal cual él es, te hago servicio. Pero bien sé que no dejarás de hallar muchos descuidos e inadvertencias, mas yo confío que lo disimularás y suplirás todo, pues sabes que es imposible que nuestra humana naturaleza deje de producir imperfectiones.

En el traducir no he guardado el rigor de la letra, porque como cada lengua tenga sus frasis, no tiene el de la una buena consonancia en la otra. Solo he procurado no apartarme del sentido que tuvieron los que lo escribieron, y aun en aquesto he excedido en algunos particulares casos, porque dicen algunas cosas que en aquesta lengua no fueran bien recebidas; y por la misma causa he cercenado algunas dellas. También he dilatado otras algunas, por hacerlas más inteligibles, que estaban cortas, porque el original las suple con los retratos de las figuras que en él están debujadas, y en esta tradución no se han podido estampar por la carestía, así del artífice como de la obra.

Asimismo he encubierto y disimulado algunos nombres de personas que en el discurso de aquesta obra se citan, por no ser católicos, que mi intento ha sido que no haya cosa con que las orejas de los píos puedan ser ofendidas, aunque bien se conoce que el mismo intento tuvieron los auctores originarios de aquestas historias, mas en su natural patria les es concedido más libertad, debajo de ser católicos, según lo muestran en aquestas historias, a las cuales yo tengo por tales con protestación que hago de que en esto y en todo lo demás me sujeto a lo que cree y enseña la sancta Madre Iglesia Católica Romana.

$Y$ digo que si en aquestos discursos hubiere alguna cosa que no sea conforme a su Sancta Institución y determinación, que la repruebo, cancelo y doy por no dicha. $Y$ debajo de aquesta protestación he emprendido el trabajo de hacer aquesta traduction, y para que, demás de los aprovechamientos de los ejemplos, el católico lector reciba contento con la variedad y maravilla de las historias que en todo el discurso de aqueste volumen se contienen; y porque en todo él había pocas (y aún casi puedo decir que ningunas) historias de casos sucedidos en España de pocos años a esta parte, recíbelo todo con la voluntad que por mí te es ofrecido.

Vale.

\section{NOTAS}

1 Este trabajo se encuadra en las líneas de investigación de dos proyectos en los que participo, comprendidos ambos en el plan Nacional de I+D+i del Ministerio de Ciencia e Innovación: "La recepción y el canon de la literatura española del Siglo de Oro en los siglos XVIII, XIX y XX" (FFI2009- 10616-subprograma FIL0), cuyo investigador principal es J. Lara Garrido, y "Pampinea y sus descendientes: 'novella' italiana y española frente a frente (I)" (FFI2010-19841-subprograma FILO), cuya investigadora principal es I. Colón Calderón.

2 M. Menéndez Pelayo (1943 [1910]: 41) pensaba que era "muy verosímil que las Historias prodigiosas se im-
Aceptado: 29 de septiembre de 2011 
primiesen por primera vez en SeviIla, donde tenía su establecimiento tipográfico Andrea Pescioni". Sin embargo, admitía no haber encontrado "noticia alguna" de esta supuesta editio princeps.

3 "Honestos digo [los cuentos], respecto de los que andan en su lengua, que para lo que en la nuestra se usa no lo son tanto que se permitieran imprimir sin hacer lo que se ha hecho, que fue quitarles lo que notablemente era lascivo y deshonesto". Evito en estas notas la referencia bibliográfica, pues los textos completos los tiene el lector a mano en este trabajo.

4 "No os maravilléis, amigo lector, si acaso hubiéredes leído otra vez en lengua toscana este agradable entretenimiento y agora le halláredes en algunas partes, no del sentido diferente, lo cual hice por la necesidad que en tales ocasiones debe usar, pues bien sabéis la diferencia que hay entre la libertad italiana y la nuestra, [...]".

5 "[...] y así las recogí [las historias], añadiendo o quitando cosas superfluas y que en el español no son tan honestas como debieran, atento que la francesa tiene algunas solturas que acá no suenan bien". Sin embargo, y pese a estas restricciones declaradas por parte de Millis, parece que o bien el criterio de rectitud era más severo por parte de los controladores del libro impreso, o bien los traductores no siempre obraron con el celo que debían. En este caso citado de las Historias trágicas de Bandello, su censor, Juan de Olave, afirmaba lo que aquí copio: "[...] habiéndole leído con atención [el libro], no hallo en él cosa que ofenda a la religión católica ni malsonante, antes muchos y muy buenos ejemplos y moralidad, fuera de algunas maneras de hablar algo desenvueltas que en la lengua francesa, donde está más extendido, deben permitirse, y en la nuestra no suenan bien, y así las he testado y enmendado otras".

6 Cuando he hallado una $m$ - delante de este grupo (trumphante), la he alterado por $n$-.

7 Ahora hay que tener en cuenta el reciente descubrimiento de la primera edición de esta obra de Straparola (González Ramírez, 2011b), que antecede en dos años a la que aquí referencio. En este trabajo mío se en- contrará una exhaustiva descripción del ejemplar localizado.

8 En el original aparece "[...] que como viesen que por causa de nuestras corruptas y abominables vidas las amenazas que continuamente Dios nos muestra [...]". He eliminado el segundo transpositor, por entender que se trata de un error por duplografía; el elemento que introduce el inciso causal ("que") convierte la frase en agramatical.

\section{BIBLIOGRAFÍA}

Chevalier, Maxime (1981): "Prólogo" a La Zucca del Doni, Barcelona, Puvill.

González Ramírez, David (2011): "En el origen de la novela corta del Siglo de Oro: los novellieri en España", Arbor, 752 (noviembre-diciembre), pp. 12211243.

González Ramírez, David (2011b): "La princeps del Honesto entretenimiento de damas y galanes (Zaragoza, 1578) de Straparola: hallazgo de una edición perdida", Analecta Malacitana, XXXIV, 2, pp. 517-528.

Menéndez Pelayo, Marcelino (1943): Orígenes de la novela [1910], III, Madrid, CSIC. 